\title{
Puerarin attenuates the inflammatory response and apoptosis in LPS-stimulated cardiomyocytes
}

\author{
YUAN YUAN ${ }^{1,2^{*}}$, HENG ZHOU $^{1,2^{*}}$, QING-QING WU ${ }^{1,2}$, FANG-FANG LI $^{1,2}$, ZHOU-YAN BIAN $^{1,2}$, \\ WEI DENG ${ }^{1,2}$, MENG-QIAO ZHOU ${ }^{1,2}$ and QI-ZHU TANG ${ }^{1,2}$ \\ ${ }^{1}$ Department of Cardiology, Renmin Hospital of Wuhan University; ${ }^{2}$ Cardiovascular \\ Research Institute of Wuhan University, Wuhan, Hubei 430060, P.R. China
}

Received September 19, 2014; Accepted October 26, 2015

DOI: $10.3892 / \mathrm{etm} .2015 .2910$

\begin{abstract}
Patients with septic shock suffer from high mortality rates, particularly when complicated by severe myocardial depression which is characterized by hypotension and a reduction in cardiac output. Inflammation is an important factor involved in the early stages of sepsis. The aim of the present study was to investigate the effect of the Chinese herbal compound puerarin $(1,5,10,20$ and $40 \mu \mathrm{M})$ on cardiomyocyte inflammatory response in a sepsis model using $\mathrm{H} 9 \mathrm{c} 2$ cardiomyocytes stimulated with $1 \mu \mathrm{g} / \mathrm{ml}$ lipopolysaccharide (LPS). The mRNA expression levels of tumor necrosis factor (TNF)- $\alpha$ and interleukin (IL)- $\beta$ were evaluated using reverse transcription-quantitative polymerase chain reaction. In addition, the protein expression levels of various factors were determined using western blot analysis. Terminal deoxynucleotidyl transferase-mediated dUTP nick end labeling was used to evaluate the apoptosis rates in the various groups, and immunocytochemical analysis was employed to determine the effect of puerarin on the nuclear translocation of p65 protein. The present study demonstrated that LPS stimulation increased IL-1 $\beta$ and TNF- $\alpha$ mRNA expression levels, as compared with the controls $(\mathrm{P}<0.05)$. Following treatment with various concentrations of puerarin, the expression levels of IL- $1 \beta$ and TNF- $\alpha$ were markedly blunted, particularly in the LPS $+40 \mu \mathrm{M}$ puerarin group ( $\mathrm{P}<0.05$ vs. the LPS group). Furthermore, puerarin administration significantly inhibited LPS-induced apoptosis in H9c2 cardiomyocytes, as determined by terminal deoxynucleotidyl transferase-mediated dUTP nick end labeling (TUNEL) staining (TUNEL positive cells: $\mathrm{LPS}+40 \mu \mathrm{M}$ puerarin group, $5.5 \%$ vs. LPS group, $10.5 \%$;
\end{abstract}

Correspondence to: Professor Qi-Zhu Tang, Department of Cardiology, Renmin Hospital of Wuhan University, 238 Jiefang Road, Wuhan, Hubei 430060, P.R. China

E-mail: qztang@whu.edu.cn

*Contributed equally

Key words: puerarin, lipopolysaccharide, inflammation, apoptosis, nuclear factor- $\mathrm{\kappa} \mathrm{B}$
$P<0.01)$. In addition, puerarin significantly decreased LPS-induced phosphorylated nuclear factor (p-NF) $-\kappa B$ p65 and Bax expression levels, and increased the expression levels of $\mathrm{Bcl}-2$, as compared with the LPS group $(\mathrm{P}<0.05)$. These data indicated that puerarin may serve as a valuable protective agent against cardiovascular inflammatory diseases.

\section{Introduction}

Septic shock is a major public health burden which occurs in $>230,000$ patients in the US each year (1) and is the main cause of morbidity and mortality in patients in non-cardiac intensive care units (2). During infection, the immune system produces a broad inflammatory cascade, triggering a systemic response which includes increased vascular permeability, myocardial depression, impairment of the coagulation cascade and multiorgan dysfunction during the late stage (3). Myocardial dysfunction is a predictor of poor prognosis in patients with septic shock (4). Its mechanisms include the attenuation of the adrenergic response at the cardiomyocyte level, alterations in intracellular calcium trafficking and blunted calcium sensitivity of contractile proteins, all of which are mediated by cytokines (5). Therapeutic management of septic shock includes addressing the existing infection and fluid therapy (6). For the treatment of sepsis-induced cardiac dysfunction, potentially useful therapies include novel inotropes, which may reduce the heart rate to cardiac oxygen expenditure and improving diastolic filling, and $\beta$-blockers which may reduce local and systemic inflammation (5) .

Lipopolysaccharide (LPS) is a major constituent of the bacterial outer membrane, and serves a crucial function in the initiation of the pathophysiological cascades (7). A reduction in LPS has been associated with improved outcomes in patients with heart disease (8). Cultured H9c2 cardiomyocytes have been shown to exhibit a marked inflammatory response to LPS stimulation (9). Therefore, the construction of a sepsis model using H9c2 cardiomyocytes may facilitate the development of novel therapeutic agents for the direct treatment of chronic heart failure.

Puerarin is the major bioactive ingredient isolated from the root of the Pueraria iobata (Willd.) (10). Puerarin has been widely studied due to its wide spectrum of pharmacological properties, which include cardioprotective (11), 
neuroprotective (12), vasodilatory, antioxidative (13), anti-inflammatory (14), anti-cancer (15) and anti-diabetic (16) effects. In our previous study, it was found that puerarin may offer a potentially effective and relatively safe approach to mitigate pressure overload-induced cardiac hypertrophy and the associated apoptosis (17). The aim of the present study was to investigate the potential of puerarin to protect against bacterial infection of the heart, by evaluating its effect on LPS-stimulated $\mathrm{H} 9 \mathrm{c} 2$ cells.

\section{Materials and methods}

Reagents. Puerarin ( $\geq 98 \%$ purity, as determined by high-performance liquid chromatography) and LPS were purchased from Sigma-Aldrich (St. Louis, MO, USA). Dulbecco's modified Eagle's medium (DMEM)/nutrient mixture F12, fetal bovine serum (FBS), trypsin, penicillin and streptomycin were purchased from Gibco-BRL (Grand Island, NY, USA). TRIzol ${ }^{\circledR}$ for total RNA extraction was obtained from Invitrogen (Thermo Fisher Scientific, Inc., Waltham, MA, USA). Transcriptor First Strand cDNA Synthesis kit and LightCycler ${ }^{\circledR} 480$ SYBR Green I Master mix were purchased from Roche Diagnostics (Basel, Switzerland). Alexa Fluor ${ }^{\circledR} 488$ goat anti-mouse immunoglobulin $\mathrm{G}(\mathrm{IgG})$ and SlowFade Gold antifade reagent with 4',6-diamidino-2-phenylindole (DAPI) were purchased from Invitrogen (Thermo Fisher Scientific, Inc.). An ApopTag ${ }^{\circledR}$ Plus Fluorescein In Situ Apoptosis Detection kit was from EMD Millipore (Billerica, CA, USA). A Bicinchoninic acid (BCA) protein assay kit was obtained from Pierce (Thermo Fisher Scientific, Inc.). Primary antibodies were from Cell Signaling Technology, Inc. (Danvers, MA, USA). IRDye $800 \mathrm{CW}$ conjugated secondary antibodies were obtained from LI-COR Biosciences (Lincoln, NE, USA).

Cell culture. H9c2 cardiomyocytes were obtained from the Cell Bank of the Chinese Academy of Sciences (Shanghai, China). The H9c2 cells were grown in high-glucose DMEM supplemented with $10 \%$ (v/v) FBS, $100 \mathrm{U} / \mathrm{ml}$ penicillin and $100 \mathrm{mg} / \mathrm{ml}$ streptomycin in a humidified $\mathrm{CO}_{2}$ incubator $(18 \mathrm{M}$; Sanyo Electric Co., Ltd., Osaka, Japan) in $5 \% \mathrm{CO}_{2}$ at $37^{\circ} \mathrm{C}$. Cells at exponential growth phase were dissociated with $0.25 \%$ trypsin, seeded in six-well culture plates at a density of $1 \times 10^{6}$ cells/well, and incubated for $24 \mathrm{~h}$. Subsequently, cells were cultured with serum-free DMEM for $12 \mathrm{~h}$. Puerarin was dissolved in dimethyl sulfoxide at a concentration of $40 \mathrm{mmol} / 1$. LPS $(1 \mu \mathrm{g} / \mathrm{ml})$ in the presence or absence of different concentrations of puerarin $(1,5,10,20$ and $40 \mu \mathrm{M})$ was added to the medium and the cells were incubated for the indicated time.

Reverse transcription-quantitative polymerase chain reaction (RT-qPCR). RT-qPCR was used to detect the mRNA expression levels of inflammatory markers, including interleukin (IL) $-1 \beta$ and tumor necrosis factor (TNF)- $\alpha$. Total RNA was isolated from cultured H9c2 cardiomyocytes using TRIzol ${ }^{\circledR}$ and their yields and purities were spectrophotometrically estimated using A260/A280 and A230/260 ratios via a SmartSpec Plus Spectrophotometer (Bio-Rad Laboratories Inc., Hercules, CA, USA). RNA ( $2 \mu \mathrm{g}$ per sample) was reverse-transcribed into cDNA using oligo(dT) primers and the Transcriptor First
Strand cDNA Synthesis kit. The PCR amplifications were quantified using a LightCycler 480 SYBR Green I Master mix. The IL-1 $\beta$ and TNF- $\alpha$ gene signals were normalized against that of glyceraldehyde-3-phosphate dehydrogenase (GAPDH). The primer used were as follows: GAPDH, forward 5'-GAC ATGCCGCCTGGAGAAAC-3' and reverse 5'-AGCCCA GGATGCCCTTTAGT-3'; TNF- $\alpha$, forward 5'-AGCATGATC CGAGATGTGGAA-3', reverse 5'-TAGACAGAAGAGCGT GGTGGC-3'; IL-1 $\beta$, forward 5'-GGGATGATGACGACC TGCTAG-3' and reverse 5'-ACCACTTGTTGGCTTATG TTCTG-3'. Briefly, following initial denaturation at $95^{\circ} \mathrm{C}$ for $5 \mathrm{~min}, 42$ primer-extension cycles were completed. Each cycle consisted of a $10 \mathrm{sec}$ denaturation step at $95^{\circ} \mathrm{C}$, a $20 \mathrm{sec}$ annealing step at $60^{\circ} \mathrm{C}$ and a $20 \mathrm{sec}$ incubation at $72^{\circ} \mathrm{C}$ for extension. A final extension step was carried out at $72{ }^{\circ} \mathrm{C}$ for $10 \mathrm{~min}$. IL-1 $\beta$ and TNF- $\alpha$ expression levels were normalized to glyceraldehyde-3-phosphate dehydrogenase (GAPDH). PCR results were quantified using the double standard curve, calculated as follows: Calibrator normalized ratio $=[$ (concentration of target)/(concentration of reference)(sample)]/[(concentration of target)/(concentration of reference) (calibrator)].

Western blot analysis. Cells were lysed in radioimmunoprecipitation assay (RIPA) lysis buffer containing $720 \mu$ l RIPA buffer, $20 \mu \mathrm{l}$ phenylmethylsulfonyl fluoride (1 $\mathrm{mM})$, $100 \mu 1$ cOmplete $^{\mathrm{TM}}$ (04693124001), $100 \mu 1$ phosSTOP $^{\mathrm{TM}}$ (04906837001; both Roche Diagnostics, Indianapolis, IN, USA), $50 \mu \mathrm{l} \mathrm{NaF}(1 \mathrm{mM})$ and $10 \mu \mathrm{l} \mathrm{Na} \mathrm{VO}_{4}$ (per ml). Protein concentration was measured using the BCA protein assay kit using a Synergy HT microplate reader (BioTek, Winooski, VT, USA). Samples of total proteins $(50 \mu \mathrm{g})$ were separated by $10 \%$ sodium dodecyl sulphate-polyacrylamide gel electrophoresis (Wuhan Goodbio Technology Co., Ltd., Wuhan, China), and transferred onto Immobilon-FL transfer membranes (EMD Millipore) in a transfer buffer containing $14.4 \mathrm{~g}$ glycine, $3.03 \mathrm{~g}$ Tris base, $800 \mathrm{ml} \mathrm{H}_{2} \mathrm{O}$ and $200 \mathrm{ml}$ methanol (per liter), at $200 \mathrm{~mA}$ for $1.5 \mathrm{~h}$. Membranes were blocked with $5 \%$ non-fat milk at room temperature for $2 \mathrm{~h}$ and incubated overnight at $4^{\circ} \mathrm{C}$ with mouse anti-human nuclear factor of kappa light polypeptide gene enhanced in B-cells inhibitor alpha ( $\mathrm{I} \kappa \mathrm{B} \alpha)$ $(1: 1,000 ; 4814)$ monoclonal antibody, the following rabbit anti-human monoclonal antibodies: phosphorylated (p)-IкB $\alpha$ $(1: 1,000 ; 2859)$; nuclear factor $(\mathrm{NF})-\kappa \mathrm{B}$ p65 (1:1,000; 8242), p-NF-кB p65 (1:1,000; 3033); B-cell lymphoma (Bcl)-2 $(1: 1,000 ; 2870)$ or the following rabbit anti-human polyclonal antibodies: Bcl-2-associated X protein (Bax) $(1: 1,000 ; 2772$; all Cell Signaling Technology, Inc.) and GAPDH (1:200; sc-25778; Santa Cruz Biotechnology, Inc.).

Membranes were then incubated with IRDye $800 \mathrm{CW}$-conjugated goat anti-rabbit immunoglobulin (Ig)G (1:10,000; 926-32211) and IRDye $800 \mathrm{CW}$-conjugated goat anti-mouse IgG $(1: 10,000 ; 926-32210)$ secondary antibodies (both LI-COR Biosciences) at $37^{\circ} \mathrm{C}$ in Odyssey ${ }^{\circledR}$ blocking buffer for $1 \mathrm{~h}$. The blots were subsequently scanned and analyzed using a two-color infrared imaging system (Odyssey; LI-COR Biosciences).

Terminal deoxynucleotidyl transferase-mediated dUTP nick end labeling (TUNEL). The detection of apoptosis was performed by TUNEL staining using the commercially 

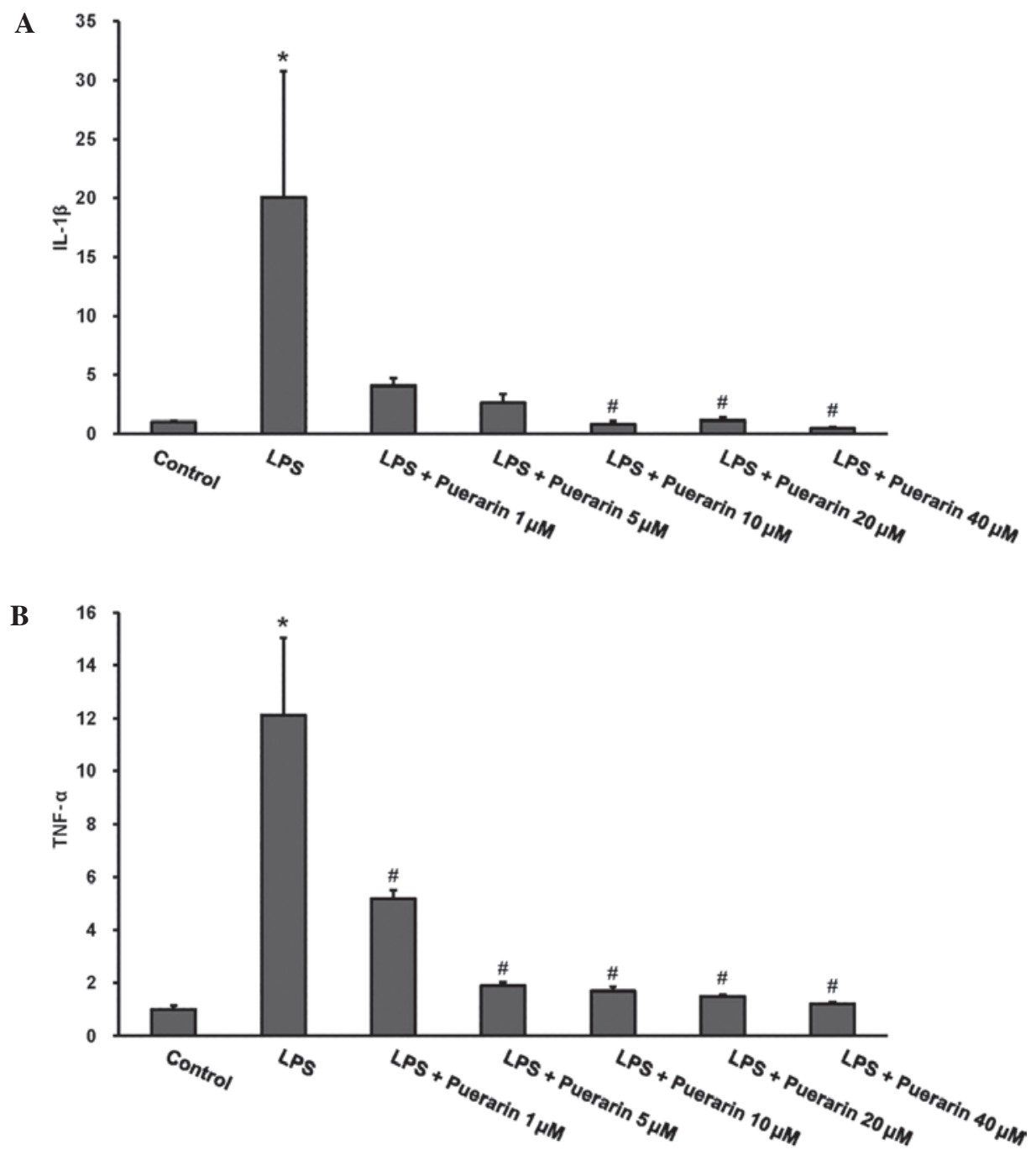

Figure 1. Effect of puerarin on mRNA expression levels of inflammatory mediators (A) IL-1 $\beta$ and (B) TNF- $\alpha$ in H9c2 cardiomyocytes. Puerarin decreased the LPS $(1 \mu \mathrm{g} / \mathrm{ml})$-induced expression of IL- $1 \beta$ and TNF- $\alpha$ in a concentration-dependent manner. ${ }^{*} \mathrm{P}<0.05$ vs. control; " $\mathrm{P}<0.05$ vs. cells treated with LPS only. LPS, lipopolysaccharide; IL, interleukin; TNF- $\alpha$, tumor necrosis factor- $\alpha$.
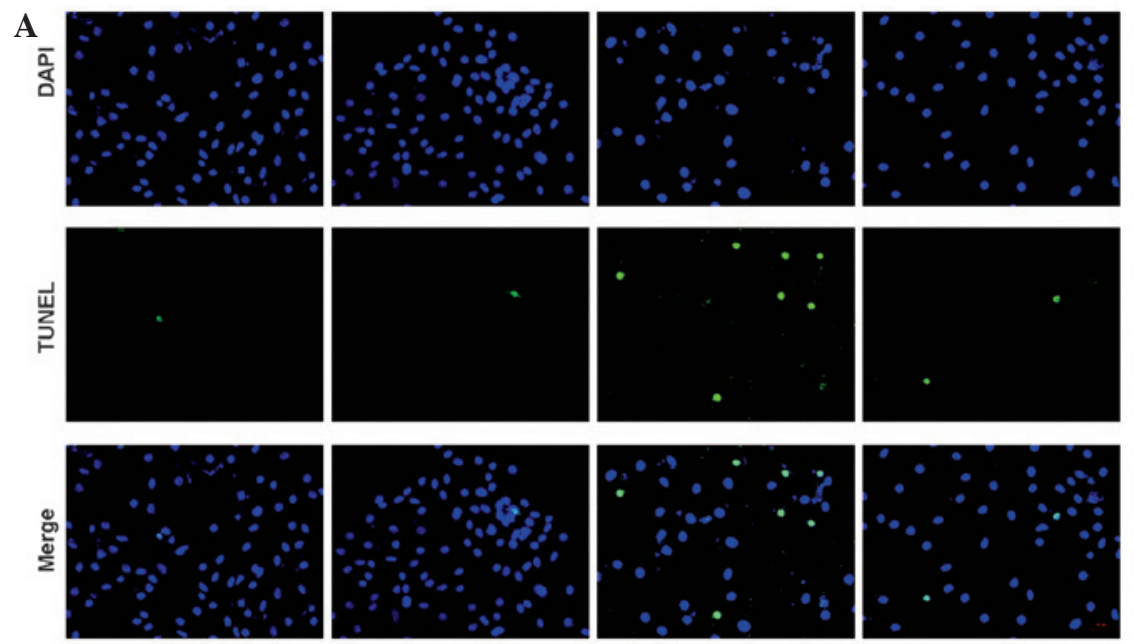

$$
\text { LPS }
$$

Pue

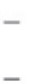

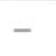$$
+
$$

B

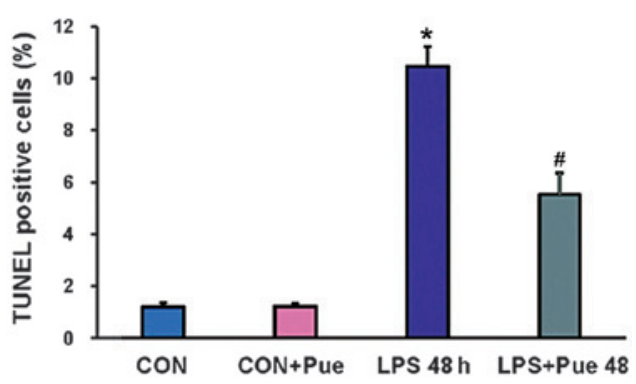

Figure 2. Effect of puerarin on apoptosis. (A and B) TUNEL staining results revealed that Pue ( $40 \mu \mathrm{M})$ attenuated apoptosis in H9c2 cardiomyocytes following stimulation with LPS $(1 \mu \mathrm{g} / \mathrm{ml}$ ) for $48 \mathrm{~h}$. (A) Electron microscopy of H9c2 cardiomyocytes (original magnification, x400). (B) Quantitative results of TUNEL staining. ${ }^{~} \mathrm{P}<0.05$ vs. control cells; ${ }^{~} \mathrm{P}<0.05$ vs. cells treated with LPS only. TUNEL, terminal deoxynucleotidyl transferase-mediated dUTP nick end labeling; CON, control; Pue, puerarin; LPS, lipopolysaccharide; DAPI, 4',6-diamidino-2-phenylindole. 
A

P-IKB $\alpha$

IKBa

Bax

Bcl-2

GAPDH
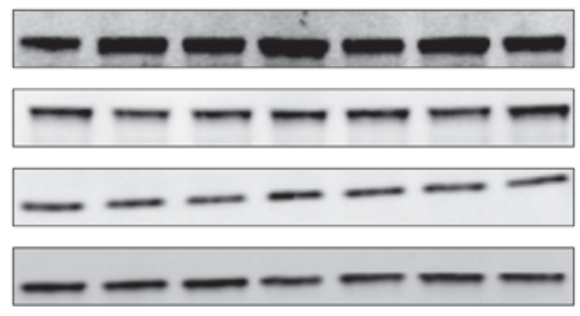

B

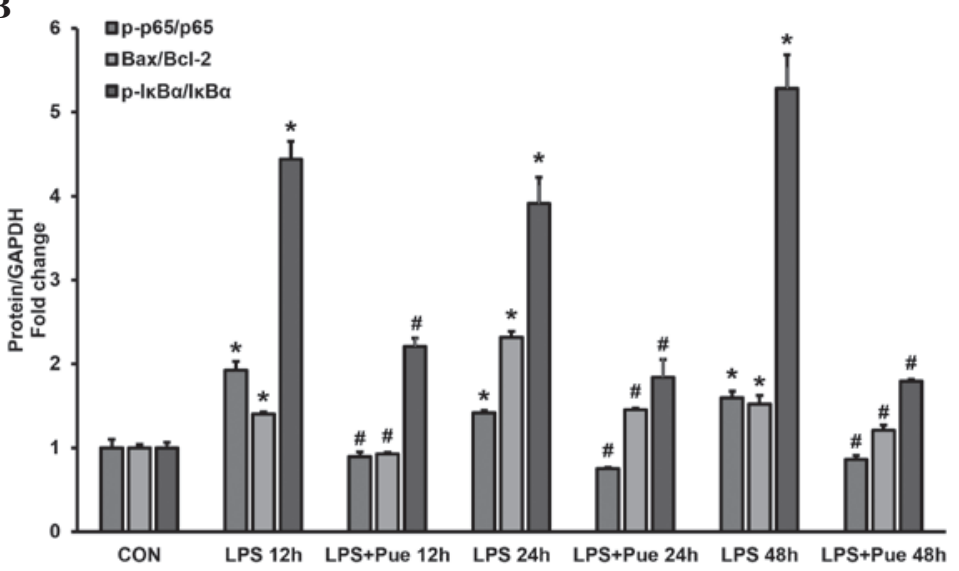

Figure 3. Effect of Pue on the activation of NF-кB pathways and the expression of Bax and Bcl-2. (A and B) Pue decreased the expression levels of p-NF- $\mathrm{kB}$ and Bax, but increased that of Bcl-2 in response to LPS treatment (1 $\mu \mathrm{g} / \mathrm{ml}$ for 12, 24 and $48 \mathrm{~h}$ ). (A) Representative western blot images. (B) Quantitative results. ${ }^{\text {"P }}<0.05$ vs. control cells; ${ }^{~} \mathrm{P}<0.05$ vs. cells treated with LPS only. LPS, lipopolysaccharide; Pue, puerarin; P, phosphorylated; NF, nuclear factor; Bcl-2, B-cell lymphoma 2; Bax, Bcl-2 associated X protein; GAPDH, glyceraldehyde-3-phosphate dehydrogenase.
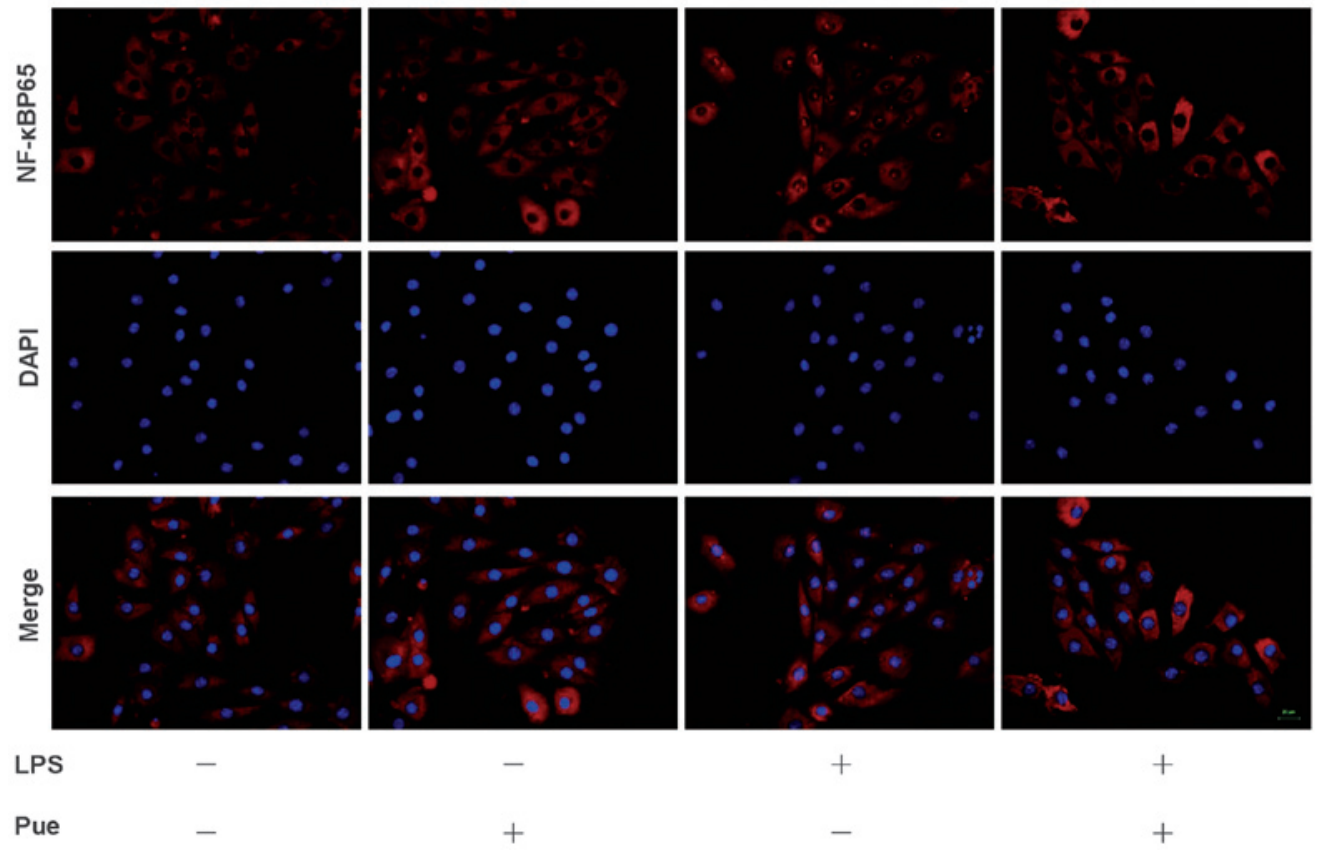

Pue

$+$

$+$

Figure 4. Pue inhibited LPS-induced nuclear translocation of NF- $\kappa \mathrm{B}$ p65, as indicated by immunocytochemistry for NF- $\mathrm{B}$ p65 localization (magnification, x400). Pue, puerarin; LPS, lipopolysaccharide; NF, nuclear factor; DAPI, 4',6-diamidino-2-phenylindole. 
available ApopTag ${ }^{\circledR}$ Plus Fluorescein In Situ Apoptosis Detection kit, according to the manufacturer's protocol. Briefly, cells on coverslips were fixed in $1 \%$ paraformaldehyde in phosphate-buffered saline (PBS) and stained with TUNEL reagents, and the nuclei were stained using DAPI. The relative number of apoptotic cells was calculated as the ratio of the number of apoptotic nuclei to the total number of nuclei.

Immunocytochemistry for $N F-\kappa B$ p 65 localization. The effect of puerarin on the nuclear translocation of p65 protein was evaluated using immunocytochemical analysis. Cells were grown on chamber slides at a concentration of $1 \times 10^{5}$ cells $/ \mathrm{ml}$ and were either not treated or treated with $40 \mu \mathrm{M}$ puerarin. Cells were fixed in a solution of methanol:acetic acid (95:5) for $20 \mathrm{~min}$ at $-20^{\circ} \mathrm{C}$ and subsequently permeabilised with $0.3 \%$ Triton X-100 (Amresco, LLC, Solon, OH, USA) at $4^{\circ} \mathrm{C}$ for 5 min. Following blocking with $8 \%$ goat serum (Abcam, Cambridge, UK) for $60 \mathrm{~min}$, the slides were incubated with rabbit polyclonal anti-p65 antibody (1:100). Following $2 \mathrm{~h}$ of incubation in a humectation chamber at $37^{\circ} \mathrm{C}$, the slides were washed with $\mathrm{PBS}$ and incubated at $37^{\circ} \mathrm{C}$ for $40 \mathrm{~min}$ with a secondary goat anti-rabbit antibody conjugated to Alexa Fluor 488 (1:200; A11008). The relative number of cells with $\mathrm{NF}-\kappa \mathrm{B}$ p65 nuclear localization was evaluated using a fluorescent microscope (BX51; Olympus Corporation, Tokyo, Japan) and images were captured using an Eclipse E800 microscope (Nikon Nederland, Amsterdam, The Netherlands).

Statistical analysis. Data are presented as the mean \pm standard error of the mean. Between-group differences were determined using two-way analysis of variance and Tukey's post-hoc analysis. Comparisons between two groups were performed using the unpaired Student's t-test. $\mathrm{P}<0.05$ was considered to indicate a statistically significantly difference.

\section{Results}

Effect of puerarin on LPS-induced proinflammatory cytokine production. As demonstrated in Fig. 1, stimulation with LPS for $24 \mathrm{~h}$ induced a significant increase in the mRNA levels of IL-1 $\beta$ and TNF- $\alpha$ in H9c2 cardiomyocytes ( $\mathrm{P}<0.05$ vs. the control). Various concentrations of puerarin (1-40 $\mu \mathrm{M})$ were used to detect its effect on the induction of IL- $1 \beta$ and TNF- $\alpha$ expression in response to LPS. Puerarin treatment markedly attenuated the LPS-induced increase in proinflammatory cytokine production in a concentration-dependent manner ( $\mathrm{P}<0.05$ vs. the LPS group).

Puerarin attenuated LPS-induced apoptosis. Only 1.2 $\pm 0.2 \%$ TUNEL-positive nuclei were detected in the control cells following the experiment. A significantly increased percentage of TUNEL-positive nuclei were observed in cells incubated with LPS (10.5 $\pm 0.8 \%$; $\mathrm{P}<0.01$ vs. the control group); however, puerarin treatment significantly reduced the percentage of TUNEL-positive cells $(5.5 \pm 0.8 \%$; $\mathrm{P}<0.01$ vs. the LPS-only group) (Fig. 2).

$\mathrm{H} 9 \mathrm{c} 2$ cardiomyocytes were treated with $40 \mu \mathrm{M}$ puerarin while exposed to $1 \mu \mathrm{g} / \mathrm{ml}$ LPS for 12,24 and $48 \mathrm{~h}$, respectively, and the Bax and Bcl-2 protein expression levels were subsequently evaluated (Fig. 3). Western blot analysis demonstrated that stimulation with LPS significantly increased the protein expression levels of Bax, while significantly decreasing those of Bcl-2 (both $\mathrm{P}<0.05$ vs. the control). Treatment with puerarin markedly reduced Bax expression to a level comparable to that of the control cells, and significantly increased Bcl-2 expression (both $\mathrm{P}<0.05$ vs. the LPS-treated cells), demonstrating that the protective antiapoptotic effect of puerarin against LPS-induced damage may be associated with the regulation of Bax and Bcl-2 expression levels by puerarin .

Puerarin blocked the LPS-induced activation of p-p65 pathways. NF- $\kappa \mathrm{B}$ activation is known to involve the regulation of LPS-induced inflammatory factor expression in cardiomyocytes (18). To further elucidate the mechanism underlying the anti-inflammatory and anti-apoptotic effects of puerarin on LPS-treated H9c2 cells, western blot analysis was used to detect the activation of $\mathrm{NF}-\kappa \mathrm{B}$. Cardiomyocytes were treated with LPS in the presence or absence of puerarin $(40 \mu \mathrm{M})$ for 12 , 24 and $48 \mathrm{~h}$ respectively. $\mathrm{NF}-\kappa \mathrm{B}$ translocation was determined by western blotting at 12, 24 and $48 \mathrm{~h}$ and by immunocytochemical analysis at $48 \mathrm{~h}$ after treatment. Puerarin appeared to block the phosphorylation and degradation of $\mathrm{I} \kappa \mathrm{B}$ in $\mathrm{H} 9 \mathrm{c} 2$ cells in response to LPS, and subsequently decreased the nuclear translocation and phosphorylated levels of NF- $\mathrm{NB}$ p65 $(\mathrm{P}<0.05$ vs. the LPS-treated cells) (Figs. 3 and 4).

\section{Discussion}

The results of the present study demonstrated that puerarin significantly attenuated the inflammatory responses of $\mathrm{H} 9 \mathrm{c} 2$ cardiomyocytes by repressing the expression levels of the proinflammatory cytokines, IL- $1 \beta$ and TNF- $\alpha$. Furthermore, puerarin exhibited a protective effect against the LPS-induced apoptosis of H9c2 cardiomyocytes by reversing LPS-induced downregulation of Bax and upregulation of Bcl-2. Therefore, the protective effect of puerarin in LPS-stimulated cardiomyocytes may be mediated by the inhibition of the $\mathrm{NF}-\kappa \mathrm{B}$ signaling cascade.

The incidence rate of cardiac dysfunction among patients with septic shock is $80 \%$ (19). Septic shock may induce hypotension, depression of myocardial systolic performance and the alteration of the diastolic function (20). In addition, myocardial dysfunction as a result of septic shock contributes to the high mortality rate associated with sepsis (21). The inhibition of cardiac inflammatory processes in sepsis may exert a beneficial effect on cardiac dysfunction (22). It has been demonstrated that the LPS-induced inflammatory response in cardiomyocytes is characterized by the induction of inflammatory mediators, such as IL-1 $\beta$ and TNF- $\alpha$ (23). In the present in vitro study, the LPS-induced expression of inflammatory factors was downregulated by puerarin treatment in a concentration-dependent manner, suggesting that puerarin may have the ability to protect cardiomyocytes against the inflammation resulting from sepsis.

In a previous study of adult male C57 mice that received $4 \mathrm{mg} / \mathrm{kg}$ LPS, increased myocardial caspase-3 activity and the number of apoptotic cells were detected (24), suggesting that apoptosis and inflammation coexist in sepsis. The balance between the upregulation and downregulation of pro-apoptotic proteins, such as Bax, and anti-apoptotic proteins, such as 
Bcl-2, determines whether the cells will undergo apoptosis $(25,26)$. The present results demonstrated that puerarin was able to counteract LPS-induced apoptosis by inhibiting the expression of Bax and increasing the expression of Bcl-2.

The role of NF- $\kappa \mathrm{B}$ activation in septic pathophysiology and the signal transduction pathways leading to $\mathrm{NF}-\kappa \mathrm{B}$ activation during sepsis/septic shock have been extensively investigated $(27,28)$. Following cell stimulation, the $\mathrm{I} \kappa \mathrm{B}$ kinase complex phosphorylates $\mathrm{I} \kappa \mathrm{B}$ proteins on specific serine residues, subsequently leading to their polyubiquitylation and proteasomal degradation (29). As a result, NF- $\kappa \mathrm{B}$ dimers accumulate in the nucleus and activate the transcription of numerous genes in various cells. Following LPS stimulation, $\mathrm{NF}-\kappa \mathrm{B}$ dimers accumulate in the nucleus of B cells and activate the transcription of IL-1 and TNF- $\alpha(30,31)$. In order to identify the mechanism underlying the cytoprotective effect of puerarin, the activation of $\mathrm{NF}-\kappa \mathrm{B}$ was evaluated. The present results indicated that treatment with puerarin resulted in a marked reduction in $\mathrm{p}-\mathrm{NF}-\kappa \mathrm{B}$ levels, and an increase in $\mathrm{I} \kappa \mathrm{B}$ levels.

In conclusion, the present results indicated that puerarin may protect against LPS-induced inflammation and apoptosis in $\mathrm{H} 9 \mathrm{c} 2$ cardiomyocytes via the inhibition of the $\mathrm{NF}-\kappa \mathrm{B}$ pathway. Furthermore, puerarin may be used as an adjuvant treatment in order to reduce cardiomycocyte inflammation and apoptosis in patients suffering from sepsis. Future studies are required in order to fully elucidate the underlying mechanisms.

\section{Acknowledgements}

The present study was supported by the National Natural Science Foundation of China (grant nos. 81300070, 81300104 and 81270303), the Specialized Research Fund for the Doctoral Program of Higher Education of China (grant no. 20130141120042) and the Fundamental Research Funds for the Central Universities of China (grant no. 2012302020212).

\section{References}

1. Murray CJ, Atkinson C and Bhalla K, Birbeck G, Burstein R, Chou D, Dellavalle R, Danaei G, Ezzati M, Fahimi A, et al: The state of US health, 1990-2010: Burden of diseases, injuries, and risk factors. JAMA 310: 591-608, 2013.

2. Martin GS, Mannino DM, Eaton S and Moss M: The epidemiology of sepsis in the United States from 1979 through 2000. N Engl J Med 348: 1546-1554, 2003.

3. Tupchong K, Koyfman A and Foran M: Sepsis, severe sepsis, and septic shock: A review of the literature. African J Emerg Med 5: $127-135,2015$.

4. Romero-Bermejo FJ, Ruiz-Bailen M, Gil-Cebrian J and Huertos-Ranchal MJ: Sepsis-induced cardiomyopathy. Curr Cardiol Rev 7: 163-183, 2011.

5. Rudiger A and Singer M: The heart in sepsis: From basic mechanisms to clinical management. Curr Vasc Pharmacol 11: 187-195, 2013

6. Seymour CW and Rosengart MR: Septic Shock: Advances in Diagnosis and Treatment. JAMA 314: 708-717, 2015.

7. Plociennikowska A, Hromada-Judycka A, Borzecka K and Kwiatkowska K: Co-operation of TLR4 and raft proteins in LPS-induced pro-inflammatory signaling. Cell Mol Life Sci 72 557-581, 2015.

8. Charalambous BM, Stephens RC, Feavers IM and Montgomery HE: Role of bacterial endotoxin in chronic heart failure: The gut of the matter. Shock 28: 15-23, 2007.
9. Frazier WJ, Xue J, Luce WA and Liu Y: MAPK signaling drives inflammation in LPS-stimulated cardiomyocytes: The route of crosstalk to G-protein-coupled receptors. PLoS One 7: e50071, 2012.

10. Zhou YX, Zhang H and Peng C: Puerarin: A review of pharmacological effects. Phytother Res 28: 961-975, 2014.

11. Chen R, Xue J and Xie M: Puerarin prevents isoprenaline-induced myocardial fibrosis in mice by reduction of myocardial TGF- $\beta 1$ expression. J Nutr Biochem 23: 1080-1085, 2012.

12. Zhu G, Wang X, Wu S, Li X and Li Q: Neuroprotective effects of puerarin on 1-methyl-4-phenyl-1,2,3,6-tetrahydropyridine induced Parkinson's disease model in mice. Phytother Res 28: 179-186, 2014.

13. Wang JW, Wang HD, Cong ZX, Zhou XM, Xu JG, Jia Y and Ding Y: Puerarin ameliorates oxidative stress in a rodent model of traumatic brain injury. J Surg Res 186: 328-337, 2014.

14. Singh AK, Jiang Y, Gupta S, Younus $M$ and Ramzan M: Anti-inflammatory potency of nano-formulated puerarin and curcumin in rats subjected to the lipopolysaccharide-induced inflammation. J Med Food 16: 899-911, 2013.

15. Kapoor S: Anti-neoplastic effects of puerarin in systemic malignancies besides colon carcinomas. Int J Pharm 443: 306, 2013.

16. Wu K, Liang T, Duan X, Xu L, Zhang K and Li R: Anti-diabetic effects of puerarin, isolated from Pueraria lobata (Willd.), on streptozotocin-diabetogenic mice through promoting insulin expression and ameliorating metabolic function. Food Chem Toxicol 60: 341-347, 2013.

17. Yuan Y,Zong J, Zhou H, Bian ZY, Deng W, Dai J, Gan HW, Yang Z, $\mathrm{Li} \mathrm{H}$ and Tang QZ: Puerarin attenuates pressure overload-induced cardiac hypertrophy. J Cardiol 63: 73-81, 2014.

18. Yu X, Jia B, Wang F, Lv X, Peng X, Wang Y, Li H, Wang Y, Lu D and Wang $H: \alpha_{1}$ Adrenoceptor activation by norepinephrine inhibits LPS-induced cardiomyocyte TNF- $\alpha$ production via modulating ERK1/2 and NF-kappaB pathway. J Cell Mol Med 18: 263-273, 2014.

19. Beraud AS, Guillamet CV, Hammes JL, Meng L, Nicolls MR and Hsu JL: Efficacy of transthoracic echocardiography for diagnosing heart failure in septic shock. Am J Med Sci 347: 295-298, 2014.

20. Lemarie J, Blet A, Bouazza Y, Boisrame-Helms J, Meziani F and Levy B: Dexamethasone and recombinant human activated protein $\mathrm{C}$ improve myocardial function and efficiency during experimental septic shock. Shock 41: 522-527, 2014.

21. Ha T, Xia Y, Liu X, Lu C, Liu L, Kelley J, Kalbfleisch J, Kao RL, Williams DL and Li C: Glucan phosphate attenuates myocardial HMGB1 translocation in severe sepsis through inhibiting NF- $\kappa B$ activation. Am J Physiol Heart Circ Physiol 301: H848-H855, 2011.

22. Ceylan-Isik AF, Zhao P, Zhang B, Xiao X, Su G and Ren J: Cardiac overexpression of metallothionein rescues cardiac contractile dysfunction and endoplasmic reticulum stress but not autophagy in sepsis. J Mol Cell Cardiol 48: 367-378, 2010.

23. Fallach R, Shainberg A, Avlas O, Fainblut M, Chepurko Y, Porat E and Hochhauser E: Cardiomyocyte Toll-like receptor 4 is involved in heart dysfunction following septic shock or myocardial ischemia. J Mol Cell Cardiol 48: 1236-1244, 2010.

24. Li X, Luo R, Jiang R, Meng X, Wu X, Zhang S and Hua W: The role of the Hsp90/Akt pathway in myocardial calpain-induced caspase-3 activation and apoptosis during sepsis. BMC Cardiovasc Disord 13: 8, 2013.

25. Alladi PA, Roy T, Singh N and Wadhwa S: Prenatal auditory enrichment with species-specific calls and sitar music modulates expression of Bcl-2 and Bax to alter programmed cell death in developing chick auditory nuclei. Int J Dev Neurosci 23: 363-373, 2005.

26. Tichý A: Apoptotic machinery: The Bcl-2 family proteins in the role of inspectors and superintendents. Acta Medica (Hradec Kralove) 49: 13-18, 2006.

27. Chen G, Zhao J, Yin Y, Wang B, Liu Q, Li P, Zhao L and Zhou H: C-type natriuretic peptide attenuates LPS-induced endothelial activation: Involvement of p38, Akt and NF-kappaB pathways. Amino Acids 46: 2653-2663, 2014

28. Walley KR: Deeper understanding of mechanisms contributing to sepsis-induced myocardial dysfunction. Crit Care 18: 137, 2014.

29. Baeuerle PA and Baltimore D: I kappaB: A specific inhibitor of the NF-kappaB transcription factor. Science 242: 540-546, 1988.

30. Grilli M, Chiu JJ and Lenardo MJ: NF-kappaB and Rel: Participants in a multiform transcriptional regulatory system. Int Rev Cytol 143: 1-62, 1993.

31. Muller JM, Ziegler-Heitbrock HW and Baeuerle PA: Nuclear factor kappaB, a mediator of lipopolysaccharide effects. Immunobiology 187: 233-256, 1993. 